\title{
An evaluation of migrants' mental health status and affecting factors in Bastam.
}

\author{
Kourosh Holakouie Naieni ${ }^{1}$, Mahshid Mojtahedzadeh Faghihi ${ }^{2}$, Hojatollah Barati ${ }^{3}$, Hamid Salehiniya $^{4}$, \\ Yousef Khani ${ }^{3 *}$ \\ ${ }^{1}$ School of Public Health, Tehran University of Medical Sciences, Tehran, Iran \\ ${ }^{2}$ Department of Clinical Psychology, Kharazmi University, Karaj, Iran \\ ${ }^{3}$ Deputy of Health, Alborz University of Medical Sciences, Karaj, Iran \\ ${ }^{4}$ Zabol University of Medical Sciences, Zabol, Iran
}

\begin{abstract}
Background and objectives: Migrants are considered as one of the groups at high risk of developing the disease. Moreover, mental health is one of the main problems facing them. The present study aims to evaluate migrants' mental health status.

Methods: Three hundred migrants settled in Bastam are selected by multistage sampling to conduct this cross-sectional study in 2016. Data are collected by 28-item General Health Questionnaire (GHQ-28) and a questionnaire containing demographic characteristics. Data analysis is performed by statistical ttests, ANOVA, and regression analysis using SPSS 16 software program. Significance level is set at 0.05 . Results: Mean score of migrants' mental health is $26.7 \pm \mathbf{0 . 8 6}$. About $44.7 \%$ of migrants enjoy good mental health and others are mentally disordered. Mental health subscales i.e. depression, anxiety, social dysfunction, and physical dysfunction are respectively seen among 9\%, 9.7\%, 6.1\%, and 7\% of migrants. The results show statistically significant association of mental health with gender, marital status, state of residence, education, employment status and type of migration $(P<0.05)$.

Discussion: Given the high prevalence of mental disorders among migrants, it is suggested to design psychological programs, offer essential services to migrants, and conduct similar longitudinal studies in other areas.
\end{abstract}

Keywords: Mental health, Migrants, Bastam.

Accepted on January 23, 2018

\section{Introduction}

Migration results from the rapid urban expansion of cities and the improvement of human life quality. People usually migrate from small towns and villages to large cities with the aim of finding a good job and making living conditions very comfortable [1]. Migration dates from the first period in human history. It brings about negative or positive consequences for migrants and even affects the residents of host society [2].

Migrants are a high-risk group with lower health status and numerous social and economic problems. People who come together at points in space-time have the same social and cultural conditions (i.e. class and ethnicity) and stable social structure. Migrants are involved in cultural and social conflict in host societies and have no detailed information about values and norms governing these societies. It causes potential problems and increases social, personal and health dangers among migrants [3]. Sometimes, people migrate due to poor conditions such as unemployment, war and natural disasters in home society. It is referred to as unsafe forced migration followed by psychological problems [2]. Since migrants often are in a bad financial situation and host city incurs an additional cost, they usually settle in downtown residential districts of the city including marginal areas or small and lowquality houses in which there is no tight security and children grow up in an unsuitable environment [4]. Poverty caused by this situation results in the loss of a golden opportunity to achieve basic literacy and the creation of many problems including reduced income, poor lifestyle habits, and health disorders especially mental ones [5]. Migrant workers have their own difficulties, engage in hard physical labor, and are faced with work-related accidents, communicable diseases, mental health disorders including stress, depression and suicide, and dangers associated with lifestyle such as alcohol and drug abuse in any society [6]. Studies show that problems related to personal and social health are more serious among migrant populations [7-9]. Mental disorders caused by stress, extended separation from family, etc. are one of the major 
problems facing migrants [10,11]. Mental health is an important issue, on which scientists, public health officials, and policy makers have recently focused so attention that world health organization has referred to it as one of the primary health care principles at the top of member states agenda. Mental health along with physical and social health is necessary for growing and developing people in a successful way [12]. Mental health is an appropriate measure of society health, plays a crucial role in the dynamism and efficiency of society, and fulfils better function [13]. Mental illnesses have come into existence since the beginning of human life and everyone always is at risk of them. It means that people may be suffering from mental illness at any age and class among which migrants are at much higher risk [14].

As mentioned before, migrants are at high risk of mental disorders. Relatively little research has been done on the health of migrants in Iran. Furthermore, it can be useful to identify effective factors in the health status of migrants. Bastam located $6 \mathrm{~km}$ North of Shahrood in Semnan province has a considerable potential to embrace migration especially seasonal one due to its distinct regional position and favourable working conditions. Therefore, this study aims to evaluate the mental health status of migrants and related factors in Bastam.

\section{Methods}

The study has a descriptive cross-sectional design. Multistage sampling is used to select a sample consisting of 300 migrants settled in Bastam in 2016. Four districts with the highest number of migrants are considered and then subjects are randomly chosen from them in proportion to the number of their residents. Inclusion criterion is to be either seasonal or permanent migrant and natives are excluded from the study. Data are collected by a trained questioner. He visits the residence place of subjects and provides a clear explanation of the study for them. All subjects voluntarily give written informed consent before the completion of questionnaire. General Health Questionnaire and demographic characteristics, such as age, gender, marital status, employment status, income, education, type of migration, insurance status, and state of residence are used to collect data. 28-item General Health Questionnaire (GHQ-28) designed by Goldberg and Hiller in 1979 to diagnose mental disorders and evaluate mental health includes four parts, namely physical function, anxiety, social function and depression that each part contains seven 4-choice questions. GHQ-28 is referred to as a useful tool for screening in Iran, which its reliability and validity have been reported $84-91 \%$ and $72-91 \%$, respectively $[15,16]$.

All items have a 4-point scoring system. Total score of each subject varies from 0 to 84 . So the higher score of general health indicates the lower quality of mental health. Cut-off point of 23 is used to determine the status of migrants suffering from mental disorders and problems. As a result, subjects having mental health score higher and lower than 23 are mentally disordered and healthy, respectively. Mental health subscales are categorized into three groups: 0-6 (healthy), 7-13 (suspected) and more than 14 (disordered) [16].

All data are analyzed by statistical t-tests, ANOVA, and regression analysis at a significance level less than 5\% using SPSS 16 software program.

\section{Results}

Subjects are in the age range of $14-80$ years and their mean age is $30.07 \pm 0.67$. Table 2 represents descriptive statistics on the sample under study. General health scores range from 5 to 74 and their mean score is $26.69 \pm 0.867$. Given the cut-off point of 23 , about $55.3 \%$ of migrants are mentally disordered and others enjoy good mental health. The mean scores of physical function, anxiety, social function and depression are $6.76 \pm$ $0.25,7.23 \pm 0.29,8.59 \pm 0.17$ and $4.59 \pm 0.30$, respectively. Based on the cut-off point of 14 selected for mental health subscales, $9 \%, 9.7 \%, 6.1 \%$ and $7 \%$ of migrants are respectively suffering from depression, anxiety, physical dysfunction and social dysfunction (Table 1).

Table 1. The mental health status of migrants.

\begin{tabular}{|c|c|c|c|c|c|}
\hline Scale & Mental health & Physical function & Social & Anxiety & Depression \\
\hline Status & $N(\%)$ & N (\%) & Function N (\%) & $\mathrm{N}(\%)$ & N (\%) \\
\hline Healthy & $119(44.7 \%)$ & $158(55.6 \%)$ & $72(25.8 \%)$ & $143(51.6 \%)$ & $200(71.7)$ \\
\hline Suspected & - & $106(37.3 \%)$ & $190(68.1 \%)$ & $107(38.6 \%)$ & $54(19.4)$ \\
\hline Disordered & $147(55.3 \%)$ & $20(7.0 \%)$ & $17(6.1 \%)$ & $27(9.7 \%)$ & $25(9.0 \%)$ \\
\hline
\end{tabular}

Table 2. The mean score of general health associated with demographic variables.

\begin{tabular}{lllll}
\hline Variable & & N (\%) & M \pm SD & P \\
\hline Gender & Male & $201(75.9 \%)$ & $25.54 \pm 0.92$ & \multirow{2}{*}{0.006} \\
\cline { 2 - 4 } & Female & $65(24.1 \%)$ & $30.24 \pm 2.08$ & \\
\hline Marital status & Single & $89(33.7 \%)$ & $27.96 \pm 1.10$ & 0.034 \\
\hline
\end{tabular}

\begin{tabular}{lllll} 
& Married & $177(66.3 \%)$ & $26.05 \pm 1.38$ & \\
\cline { 2 - 4 } Type of migration & Seasonal & $173(65.6 \%)$ & $26.15 \pm 1.0$ & 0.045 \\
\cline { 2 - 4 } & Permanent & $93(34.4 \%)$ & $25.54 \pm 0.92$ & \\
\hline Insurance status & Insured & $204(76.3 \%)$ & $26.32 \pm 1.01$ & \multirow{2}{*}{0.219} \\
\cline { 2 - 4 } & Non-insured & $62(23.7 \%)$ & $27.90 \pm 1.70$ & \\
\hline State of residence & Owner & $83(29.7 \%)$ & $23.42 \pm 1.71$ & 0.002 \\
\hline
\end{tabular}




\begin{tabular}{llll}
\hline \multirow{2}{*}{ Education } & Tenant & $146(59.9 \%)$ & $26.59 \pm 1.08$ \\
\cline { 2 - 4 } & Relative's house & $27(10.4 \%)$ & $34.37 \pm 2.23$ \\
\cline { 2 - 4 } & Uneducated & $46(16 \%)$ & $26.56 \pm 1.66$ \\
\cline { 2 - 4 } & Primary school & $67(27.5 \%)$ & $21.04 \pm 1.32$ \\
\cline { 2 - 4 } & Middle school & $47(19.5 \%)$ & $32.55 \pm 1.66$ \\
\cline { 2 - 4 } Employment status & High school & $72(25.8 \%)$ & $27.31 \pm 1.68$ \\
\cline { 2 - 4 } & Collegiate & $30(11.1 \%)$ & $27.20 \pm 4.14$ \\
\cline { 2 - 4 } & Worker & $144(55 \%)$ & $25.88 \pm 0.99$ \\
\cline { 2 - 4 } & Employed & $18(7.9 \%)$ & $36.00 \pm 6.08$ \\
\hline & Farmer & $6(2.1 \%)$ & $19.00 \pm 2.39$ \\
\cline { 2 - 4 } & Unemployed & $6(2.1 \%)$ & $28.00 \pm 2.30$ \\
\cline { 2 - 4 } & Housewife & $38(13.1 \%)$ & $22.97 \pm 1.95$ \\
\cline { 2 - 4 } & Self-employed & $30(11 \%)$ & $28.63 \pm 2.22$ \\
\cline { 2 - 4 } & Student & $12(4.1 \%)$ & $33.66 \pm 6.08$ \\
\cline { 2 - 4 } & Retired & $11.00 \pm 1.73$ \\
\hline
\end{tabular}

The results show that mental health is significantly correlated with gender, marital status, state of residence, education, employment status and type of migration $(\mathrm{P}<0.05)$. The mental health status of males is better than that of females. Married subjects enjoy better mental health than single ones. Permanent migrants are in better mental condition than seasonal ones. Subjects living with relatives have a poorer mental health than others (Table 2). Females show more anxiety and physical dysfunction than males, indicating the relationship between gender and anxiety and physical function is significant $(\mathrm{P}<0.05$, Table 3).

Table 3. Comparing the mean scores of mental health subscales in terms of gender.

\begin{tabular}{llll}
\hline Scale & Variable & M \pm SD & P \\
\hline Depression & Male & $4.39 \pm 0.34$ & \multirow{2}{*}{0.272} \\
\cline { 2 - 3 } & Female & $5.19 \pm 0.65$ & \\
\hline Anxiety & Male & $6.75 \pm 0.31$ & \multirow{2}{*}{0} \\
\cline { 2 - 3 } & Female & $8.71 \pm 0.71$ & \multirow{2}{*}{0.0123} \\
\hline Social function & Male & $8.71 \pm 0.20$ & \\
\cline { 2 - 3 } & Female & $8.22 \pm 0.33$ & \\
\hline Physical function & Male & $6.31 \pm 0.26$ & \\
\cline { 2 - 3 } & Female & $8.11 \pm 0.62$ & \\
\hline
\end{tabular}

\section{Discussion}

The present study aims to evaluate the mental health status of migrants in Bastam. The results of the study show that 55.3\% of migrants have earned a general health score higher than 23 , suggesting that they are mentally disordered. This finding is in a good agreement with Mohammadian et al. reporting mental disorders among $55.6 \%$ of migrants $[17,18]$.

On the contrary, Manesh et al. showed that the prevalence of mental disorders is in the range of $18 \%$ to $23 \%$ among the Iranian population, in agreement with several studies on the other populations [7,19-22]. Thus, mental disorders are especially prevalent among migrants, resulting from problems facing them [11].

Age, cultural and social conflict, separation from family and relatives, lack of pivotal social role, unemployment or job insecurity, hard physical labor, and discrimination must be taken into account since they can damage the mental health of migrants $[10,11]$.

In this study, depression, anxiety, physical dysfunction and social dysfunction are respectively reported among $9 \%, 9.7 \%$, $6.1 \%$ and $7 \%$ of migrants, which are at a higher level than those of Afghan migrants settled in Tehran [11]. It indicates the higher prevalence of mental disorders among migrants, which can be attributed to the separation from family and unfavourable living conditions.

There is a correlation between mental health and gender. It is similar to the findings obtained from Mohammadian et al. $[17,18,23]$. Mental health is significantly associated with marital status, in a good agreement [23]. It is found the same relationship between type of migration and mental as Warfa et al. [24].

In general, migrants have poor mental health and most of them are suffering from mental disorders. In fact, geographical mobility may create great stress, lead to family disruption, affect mental health, and cause mental disorders [24].

One of the most important social system objectives is to meet the basic health needs, improve the quality of life, and draw attention to living conditions and health status. It involves evaluating the mental health of people to think carefully about the health improvement and provide a proper balance between migrants and natives for the prohibition of discrimination between them increasing mental disorders among migrants [10].

Mental health improvement, especially among migrants with two different cultural systems gives rise to the high quality of their life. Relatively little research has been done on the health of migrants in Iran.

Migrants account for a large part of society and have particular needs to be emphasized and satisfied due to their adaptation to host society. Accordingly, the mental health of migrants is of great importance and needs to be given more attention.

\section{Conclusion}

The following conclusions can be drawn from the obtained results. Migrants are in poorer mental condition than others. However, there is little research on migration. Thus, it is suggested to provide healthcare and cultural programs for migrants, especially in spring and summer to improve their 
health, and conduct similar longitudinal studies in different parts of the country to identify risk factors.

\section{Acknowledgement}

The authors would like to thank all people especially migrants for giving great help to conduct this study.

\section{References}

1. Pumariega AJ, Rothe E, Pumariega JB. Mental health of immigrants and refugees. Community Mental Health J 2005; 41: 581-597.

2. Jamshidiha G, Anbari M. Social belonging and its impact on the return of Afghan refugees. Tehran Univ Electronic J Database Soc Sci Lett 2003; 23: 44-68.

3. Zare Shahhamadi A. Role of Iraqi refugees living in the Yazd city in the social problems. Geography Dev Iran J 2003; 1: 50-67.

4. Entzinger H, Biezeveld RL. Benchmarking in immigrant integration. ERCOMER 2003.

5. Beiser M, Hou F, Hyman I, Tousignant M. Poverty, family process, and the mental health of immigrant children in Canada. Am J Public Health 2002; 92: 220-227.

6. Adhikary P, Keen S, Van Teijlingen E. Health issues among Nepalese migrant workers in the middle East. Health Sci J 2011; 5: 169-175.

7. Ghorbani A, Golchin M. Investigating the mental health status of women in Qazvin Province, 2008. J Qazvin Univ Med Sci 2011; 15: 56-62.

8. Newbold KB, Danforth J. Health status and Canada's immigrant population. Soc Sci Med 2003; 57: 1981-1995.

9. Van Bergen DD, Smit JH, Kerkhof AJ, Saharso S. Gender and cultural patterns of suicidal behavior: young Hindustani immigrant women in the Netherlands. Crisis 2006; 27: 181-188.

10. Finch BK, Kolody B, Vega WA. Perceived discrimination and depression among Mexican-origin adults in California. J Health Soc Behav 2000; 295-313.

11. Mohammadian M, Dadfar M, Bolhari J, Karimi Keisami E. Screening for mental disorders among Afghan immigrants residing in Tehran. Iran J Psychiatr Clin Psychol 2005; 11: 270-277.

12. Epp J. Achieving health for all: A framework for health promotion. Health Promotion Int 1986; 1: 419-428.

13. Sadeghian E, Heidarian Pour A. Stressors and mental health status among students of Hamadan University of Medical Sciences. J Hayat 2009; 15: 71-80.
14. Stronks K. Commentary: Public health research among immigrant populations: still a long way to go. Eur J Epidemiol 2003; 18: 841-842.

15. Besharat M. Reliability and validity of a short form of the mental health inventory in an Iranian population. Sci J Forensic Med 2009.

16. Noorbala A, Mohammad K. The validation of general health questionnaire- 28 as a psychiatric screening tool. Hakim Res J 2009; 11: 47-53.

17. Kalafi U, Ostovar A, Haghshenas A. Mental Health status of afghan emigrants living in Shiraz. Iran J Psychiatr Clin Psychol 1999; 5: 4-11.

18. Blight KJ, Ekblad S, Persson JO, Ekberg J. Mental health, employment and gender. Cross-sectional evidence in a sample of refugees from Bosnia-Herzegovina living in two Swedish regions. Soc Sci Med 2006; 62: 1697-1709.

19. Ehsanmanesh M. Epidemiology of mental disorders in Iran: A review of research findings. Sci Inform Database 2001.

20. Mehri A, Sedighy Some-Koochak Z. Assessment of mental health status and some related factors among students of Sabzevar Universities in 2010. Med Sci J Islamic Azad Univ Tehran Med Branch 2012; 24: 1293-1304.

21. Safi KF, Bit SK, Hajatzadeh M. Surveying the mental health of Ahvaz Jundishapur medical sciences university nursing interns. Sci Inform Database 2011.

22. Tavakolizadeh J, Khodadadi Z. Assessment of mental health among freshmen entering the first semester in Gonabad University of Medical Sciences in 2009-2010. Horizon Med Sci 2010; 16: 45-51.

23. Iman M, Moradi GM. The examination of the relation between acculturation stress and mental health: Kermanshah as a case study. 2009.

24. Warfa N, Bhui K, Craig T, Curtis S, Mohamud S, Stansfeld S. Post-migration geographical mobility, mental health and health service utilisation among Somali refugees in the UK: a qualitative study. Health Place 2006; 12: 503-515.

\section{*Correspondence to}

Yousef Khani

Deputy of Health

Alborz University of Medical Sciences

Iran

Email: y.khani63@yahoo.com 